\title{
O PROGRAMA INSTITUCIONAL DE BOLSAS DE INICIAÇÃO A DOCÊNCIA: REFLEXÕES SOBRE AS AÇÕES DA LINHA DE AÇÃO EDUCAÇÃO AMBIENTAL
}

\author{
Silvana do Nascimento Silva ${ }^{1}$ \\ Carlos Frederico Bernardo Loureiro²
}

Resumo: No presente artigo faz-se um relato de experiência do Programa Institucional de Bolsas de Iniciação a Docência (Pibid), desenvolvido na Universidade Estadual do Sudoeste da Bahia, que tem por objetivo proporcionar aos sujeitos envolvidos o desenvolvimento de ações colaborativas no exercício da prática pedagógica. $\mathrm{Na}$ formação inicial e continuada de professores, na linha de ação Educação ambiental, problematizam-se aspectos socioambientais que coexistem nas comunidades escolar e externa, elaborando-se ações educativas pautadas no envolvimento colaborativo e participativo. Dentre outras, são descritas no texto: rodas de estudos, estudos do meio, encontros na escola, diários de campo e elaboração de materiais didáticos, indicando os resultados alcançados.

Palavras-chave: Educação Ambiental; Pibid; Formação de Professores.

\footnotetext{
${ }^{1}$ Universidade Estadual do Sudoeste da Bahia. Grupo de Pesquisa em Educação Ambiental e Formação de Professores. Programa Institucional de Bolsas de Iniciação a Docência (Pibid-Uesb-Capes). E-mail: siluesb@hotmial.com

${ }^{2}$ Universidade federal do Rio de Janeiro. Programa de Pós-Graduação em Educação. Pesquisador CNPq. E-mail: fredericoloureiro89@gmail.com
} 


\section{O Programa Institucional de Bolsas de Iniciação Docência (Pibid)}

O Programa Institucional de Bolsas de Iniciação a Docência (Pibid) é um projeto desenvolvido em parceria com a Coordenação de Aperfeiçoamento de Pessoal de Nível Superior (Capes), que tem por objetivo proporcionar aos sujeitos envolvidos - licenciandos, professores da escola básica e professores universitários - o desenvolvimento de ações colaborativas no exercício da prática pedagógica.

Este programa viabiliza a formação inicial e contínua de professorespesquisadores, pois, dentre suas principais ações, destacam-se o estudo etnográfico, interpretado como um processo investigativo sobre a cultura escolar e a pesquisa-ação, como uma investigação pautada no desenvolvimento de ações de intervenção participativa.

Dentro dessa perspectiva, originou-se o Pibid-Uesb Microrrede EnsinoAprendizagem-Formação, ressignificando a formação inicial e continuada de professores. Este programa abrange os três campi da Universidade Estadual do Sudoeste da Bahia (Uesb), mas a linha de ação que é abordada neste texto faz parte do Subprojeto Interdisciplinar do Campus Universitário de Jequié-BA. Integram os subprojetos deste campus os cursos de Licenciatura em Ciências Biológicas, Educação Física, Pedagogia, Letras, Matemática, Química, Teatro e Dança. Em 2014, contamos com dez subprojetos e 21 linhas de ação (PibidUesb, 2014).

O Subprojeto Interdisciplinar é composto pelas seguintes linhas de ação: Educação ambiental, Educação do campo, Educação especial e Educação de jovens e adultos. Apresentamos neste relato as ações vivenciadas na linha de ação Educação ambiental.

A Educação ambiental (EA) é compreendida como uma prática social em que se destacam problematizações em torno dos aspectos socioambientais que analisados, debatidos e socializados. A problematização nos permite elaborar ações educativas a serem trabalhadas no contexto escolar priorizando o engajamento colaborativo e participativo entre os sujeitos envolvidos.

\section{Educação ambiental}

A denominação educação ambiental se constituiu na radicalidade questionadora dos anos de 1960. Seu contexto de criação era composto por pelo menos quatro "vetores" que foram decisivos para a definição dos seus princípios, diretrizes e orientações político-pedagógicas: (1) movimentos sociais diversos; (2) o movimento de contracultura; (3) os padrões de conservação da natureza promovidos por antiga tradição científica e por grupos voltados para garantir a biodiversidade e (4) os intensos debates políticos e filosóficos da ecologia política, com caráter de questionamento radical à sociedade capitalista e aos modos de vida dominantes (eurocêntricos) e seus intrínsecos processos de uso insustentável dos recursos naturais e expropriação do trabalho. 
No Brasil, a educação ambiental teve seu início reconhecido publicamente nos anos de 1970, durante a ditadura militar, por dentro do aparato estatal ambiental. Nessa época, não poderia ser diferente, a educação ambiental foi reduzida pelo discurso dominante à transmissão de conhecimentos ecológicos, ao ensino de técnicas e de comportamentos ecologicamente viáveis, mesmo que pudéssemos identificar algumas falas e práticas mais políticas em pessoas e grupos.

Nos anos de 1980, com o processo de "redemocratização", esse cenário começa a se reverter, o que não significou um imediato diálogo entre educação e educação ambiental. Nessa época, a organização dos primeiros grupos ambientalistas que afirmavam que as causas dos problemas ambientais estavam na organização social e a incorporação da questão ambiental por educadores populares, adeptos do método Paulo Freire, além dele mesmo, são os responsáveis diretos por uma alteração discursiva com críticas aos reducionismos biológicos, à simplificação da educação à transmissão de conhecimentos e a sua instrumentalização.

A aproximação entre educação ambiental e educação, no entanto, estava apenas começando, e com um grau de criticidade bastante modesto na análise das políticas públicas em educação e suas implicações nas instituições escolares e no tratamento da questão ambiental. Após a realização da Rio 92, há um aumento considerável no número de professores e demais trabalhadores da educação, escolas e universidades envolvidos com a educação ambiental. E, ao longo da década de 1990, observam-se as primeiras ações concretas de maior envergadura do MEC, que promove iniciativas de formação de professores, cria o primeiro Programa Nacional de Educação Ambiental e institui o tema transversal meio ambiente nos Parâmetros curriculares nacionais.

É de fato, na década de 2000, particularmente após 2002, que se pode dizer que a relação se consolida. Nesse contexto, o MEC intensifica várias ações e consegue contribuir para praticamente universalizar a presença da educação ambiental nas escolas. Em pesquisa realizada em 2006 por este ministério, cerca de $96 \%$ das escolas brasileiras declararam realizar a educação ambiental (seja como projeto, disciplina, tema transversal, via projeto político pedagógico, integração entre duas ou mais disciplinas, entre outras opções não necessariamente excludentes entre si), com patamares quantitativos bastante equivalentes entre todas as regiões do Brasil.

No entanto, a ação desde então se voltou para um movimento do exterior para o interior escolar, com reduzida influência da Coordenação Geral de Educação Ambiental do MEC junto às políticas centrais da educação brasileira (currículo, formação de professores, gestão escolar, autonomia da escola pública etc.). Mais do que isso, como historicamente a educação ambiental não se constituiu no diálogo e na disputa em torno das principais políticas de educação, no geral, o máximo que consta dessas políticas é uma 
menção à sustentabilidade como princípio, sem rebatimento prático e sem que - campo da educação ambiental reflita de forma madura sobre suas implicações e a quem servem.

Mais do que isso, as políticas de educação ambiental são vagas, quando falam em formação inicial e continuada dos profissionais da educação, apesar de esta ser a principal demanda dos professores identificada na referida pesquisa feita pelo MEC em 2006, além de ser um direito destes e dos educandos.

Em sendo uma necessidade reconhecida e uma demanda exigida por professores, é fundamental a constituição de coletivos que enfrentem esses desafios. Que avancem na produção de conhecimentos que permitam não só compreender criticamente os processos de formação, mas também ajudem na proposição de caminhos transformadores da realidade. Que sejam elementos de reflexão sobre políticas educacionais de formação e de defesa do caráter efetivamente público de tais políticas na garantia do ambiente como bem comum.

Carvalho (2008) nos chama atenção para o fato de que, na esfera educativa, se observa a formação de consenso da necessidade de problematização da EA. O trabalho pedagógico torna-se de extrema importância para a compreensão das relações que premiam o campo ambiental relacionadas não apenas com os fatores naturais - natureza -, mas também com as dimensões sociais e culturais que regem a interação do homem com o ambiente.

Para Carvalho (2008), ocorre com frequência, no trabalho pedagógico em $E A$, a socialização da visão naturalista, que reduz o ambiente à natureza, sem vínculos com os demais fatores que interagem com o meio. A ação educativa deve ser voltada para uma educação ambiental crítica, com intervenção político-pedagógica direcionada para o estabelecimento de uma sociedade de direitos e ambientalmente justa.

No contexto ora exposto, torna-se necessário que os estudantes possam perceber que, ao longo da caminhada humana, todos os tipos de relação estão conectados ao contexto geográfico, ecológico e cultural, em que se produz e reproduz uma formação social determinada (LEFF, 2005; LOUREIRO, 2006). Esse tipo de formação social vai caracterizar as formas de o ser humano se relacionar e se apropriar dos recursos da natureza.

Para que os estudantes tenham uma visão mais crítica e transformadora dos problemas ambientais, como, por exemplo, sobre a exploração dos recursos naturais e a relação ou interferência do homem no ambiente, as discussões em sala de aula devem propiciar uma abordagem não só acerca da pressão que exerce o crescimento da população sobre os limites dos recursos naturais, mas, sobretudo, uma explicação voltada para o âmbito econômico e social (LEFF, 2005), sem perder de vista que as relações entre as classes sociais atuam distintamente sobre as diferenças organizacionais da sociedade, 
ou seja, sobre as assimetrias de poder existentes nela (GERHARDT; ALMEIDA, 2005; LOUREIRO, 2002).

Os ministérios do meio ambiente e da educação no Brasil também mobilizam pesquisas e debates na tentativa da problematização dos temas ambientais nas escolas (BRASIL, 2007). No estudo de Loureiro e Cassio (2007) sobre o que fazem as escolas em termos de EA, os autores priorizam alguns pontos essenciais para um trabalho profícuo neste espaço: dedicar especial atenção ao processo de formação de educadores ambientais, ampliar e fomentar o envolvimento de professores, gestores, funcionários e alunos, garantir a participação de professores do ensino fundamental em eventos e abrir ampla discussão nacional envolvendo os diversos setores que constituem a sociedade contemporânea.

O estudo de Veloso (2007) contribui também para a reflexão sobre o trabalho com a EA na escola, na medida em que busca destacar o projeto político pedagógico como uma rede das intencionalidades dos sujeitos sociais que interagem no contexto escolar, e como o currículo escolar contribui para a formação de tais sujeitos voltados para as questões da sustentabilidade.

A partir deste pressuposto, o Pibid-Microrrede Ensino-AprendizagemFormação, especificamente no subprojeto interdisciplinar em EA se constituiu para o desenvolvimento de atividades colaborativas em torno de execução de ações que possam propiciar a problematização da EA no contexto escolar.

\section{Delineamento metodológico}

O grupo que compõe a linha de ação EA é composto por 22 bolsistas, dos quais 18 são de iniciação à docência (ID), três professoras supervisoras e uma coordenadora da linha de ação. Os bolsistas ID são todos do curso de licenciatura em Ciências Biológicas. O que nos fez levantar o questionamento sobre o real conhecimento sobre EA: será que os licenciandos dos cursos da Uesb percebem EA apenas como preocupação das ciências biológicas? $O$ edital para seleção foi aberto para todos os licenciandos dos demais cursos. Contudo, como existiam outros subprojetos específicos (Química, Letras, Pedagogia, Matemática, Educação Física, Teatro e Dança), acreditamos que os licenciandos preferiram optar pela sua área de atuação.

O grupo interdisciplinar EA tem por finalidade alcançar os seguintes objetivos: aproximar os licenciandos da realidade escolar a partir de uma visão crítica sobre educação ambiental, discutir referências teórico-metodológicas do campo da EA, realizar intervenções colaborativas com os licenciados, comunidades escolar e local, produzir conhecimento a partir das ações vivenciadas, dentre outros.

O subprojeto interdisciplinar foi elaborado colaborativamente pelas coordenadoras das linhas de ação específicas, a partir desse princípio e se pauta pelas especificações do Edital 010/2014, publicado pela Capes. O que foi 
um momento de desafio na medida em que não houve propostas preestabelecidas, e sim um pensar colaborativo dentro das aproximações entre as linhas de ação do mesmo subprojeto, e de subprojetos específicos. Desta forma, foi se constituindo o Projeto Institucional 2014 (PIBID-UESB, 2014). Neste relato de experiência, limitamo-nos a apresentar e discutir as seguintes ações: a) rodas de conversas; b) estudo do meio; c) encontros na escola; d) diário de campo; e) planejamento e elaboração dos materiais didáticos; f) monitoria didática; g) socialização dos resultados; e h) avaliação.

Neste contexto, os bolsistas utilizaram duas vertentes metodológicas: a) o estudo etnográfico que descreve o conjunto de entendimentos e de conhecimento da cultura de um determinado grupo (WIRLEWICKI, 2001). Desta forma, ao longo do ano letivo de 2014/2015 passaram a frequentar as escolas parceiras, com o objetivo de conhecer a cultura escolar. As observações realizadas nesse processo são anotadas no diário de bordo e socializadas nas rodas de conversas; e b) a pesquisa-ação compreendida como uma "modalidade de investigação que articula dialeticamente a pesquisa e a ação e tem por finalidade transformar a realidade a partir da resolução de problemas" (MIRANDA, 2012, p.25). Imersos no contexto escolar, os bolsistas realizam intervenções que são elaboradas conjuntamente com os estudantes do ensino fundamental.

\section{Resultados e discussão}

a) Rodas de conversas: nesta ação, selecionamos alguns textos referentes à educação ambiental que pontuassem criticamente os aspectos socioambientais. Desta forma, os textos selecionados foram apresentados pelos bolsistas de forma a gerar discussões sobre o tema apresentado. Também discutimos questões referentes as demais ações em desenvolvimento, principalmente a apropriação dos referenciais e sua aplicação no contexto escolar e no cotidiano dos bolsistas. A seguir uma das bolsistas pontua sobre o estudo prévio realizado nas rodas de conversas.

\footnotetext{
A importância do Pibid é dada através de seu principal objetivo, a iniciação à docência, que nos insere no ambiente escolar por meio das observações, intervenções e vivências, em que temos a experiência de atuar e participar do planejamento das aulas, do estudo prévio para as intervenções, escrita dos relatórios e reuniões para compartilhamento de nossos aprendizados. Creio que todo o conhecimento adquirido com o auxílio do Pibid levará para minha futura ação como professora, e também para minha vida particular, pois partilhar de momentos com os alunos, os professores, orientadora, colegas e coordenadoras, me ajuda a evoluir também como indivíduo (Daiane, bolsista de Iniciação a Docência).
} 
A roda de conversa (Figura 1) na nossa linha de ação configura-se como uma técnica de estudo, e abre possibilidades para a criação de um espaço em que os "os sujeitos estabelecessem um espaço de diálogo e interação, ampliando suas percepções sobre si e sobre o outro no cotidiano escolar" (MELO; CRUZ, 2014, p,32).
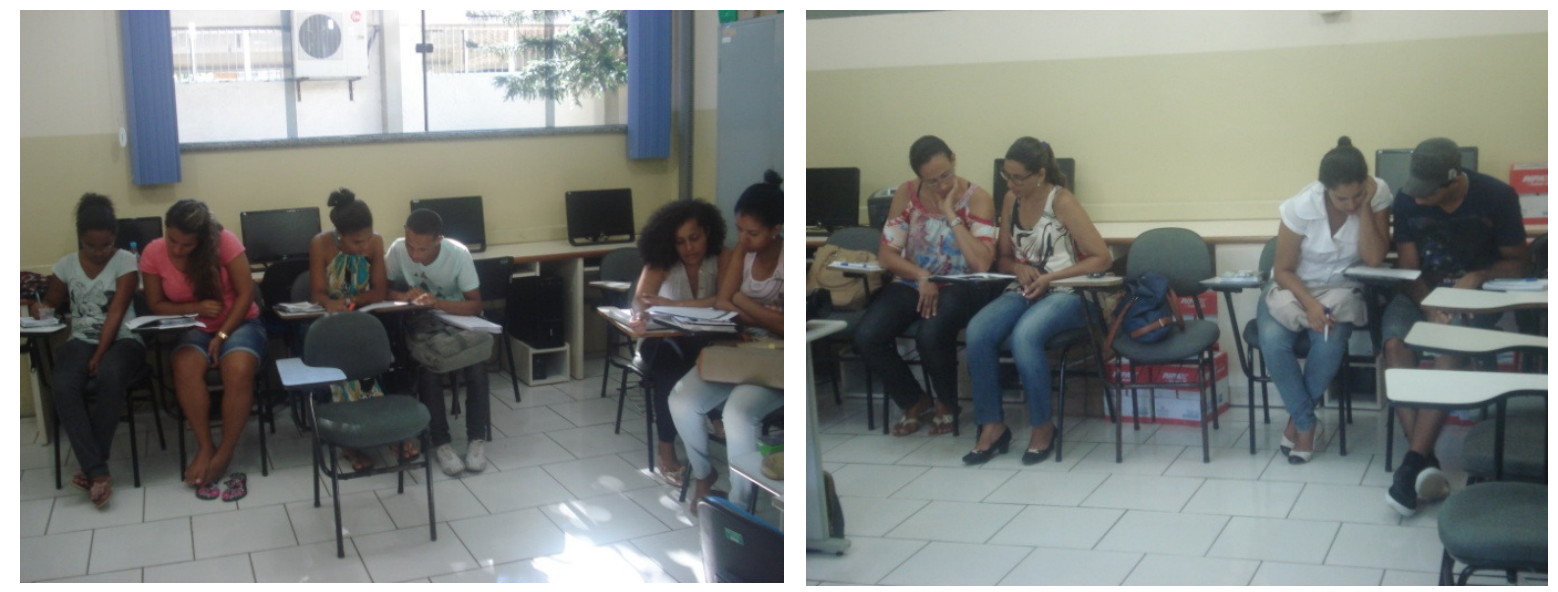

Figura 1: Roda de conversa realizada na sal multimeios do Laboratório de Ensino de Biologia . Fonte: autoria própria

b) Estudo do meio: os bolsistas ID são encaminhados às escolas parceiras, uma, localizada na área urbana e a outra, no campo. Nas escolas, eles são orientados pelas suas respectivas professoras supervisoras para realizar 0 estudo do contexto escolar. Contamos com três supervisoras. Desta forma, foram constituídos três grupos de estudo. No momento das rodas de conversa é que socializamos os resultados dos estudos e elaboramos conjuntamente as ações socioambientais. A partir destes estudos é que desenvolvemos as duas modalidades de compreensão e investigação das peculiaridades do chão da escola, denominadas estudo etnográfico e pesquisa-ação realizado de forma colaborativa entre Universidade-PibidEscola. A seguir um depoimento de uma das professoras supervisoras:

\begin{abstract}
Em resumo a esta parceria Uesb- Pibid -Escola parceira, confesso que os estudos realizados não trouxe apenas conhecimentos novos, percebo que novos também esta sendo os nossos olhares para cada detalhe, para cada ação, ou seja para a reformulação de nossas metodologias, de nossas atitudes e hábitos. Quanto aos alunos, acredito que estão também envolvidos por uma experiência nova, mais concreta (Neila, professora supervisora).
\end{abstract}

O estudo do meio é visto como uma metodologia que possibilita integrar a "prática social que envolve ensino, pesquisa e formação" (LLARENA, 2009, p. 40), o que contribui para o desenvolvimento de um trabalho interdisciplinar 
possibilitando novos olhares e novos saberes a partir do pensar criticamente sobre educação ambiental.

Fruto das observações realizadas pelos bolsistas, as pesquisas realizadas se processam de forma colaborativa com os estudantes das escolas parceiras. O Quadro 1 ilustra três trabalhos de natureza qualitativa, em que a pesquisaação é a abordagem metodológica utilizada:

Quadro 1 - Trabalhos de conclusão de curso (TCC) em andamento, desenvolvidos pelos bolsistas ID originados pela pesquisa-ação realizada no Pibid Interdisciplinar - Educação Ambiental.

\begin{tabular}{|c|c|c|}
\hline Título & Objetivo & Metodologia \\
\hline $\begin{array}{l}\text { Programa Institucional de Bolsas de } \\
\text { Iniciação a Docência: análise da } \\
\text { prática de construção de viveiro } \\
\text { como ferramenta } \\
\text { problematização da Educação } \\
\text { Ambiental e fortalecimento entre } \\
\text { escola e comunidade local. }\end{array}$ & $\begin{array}{l}\text { Analisar as contribuições e } \\
\text { limitações da construção de um } \\
\text { viveiro de plantas nativas como } \\
\text { ferramenta para a problema- } \\
\text { tização da educação ambiental no } \\
\text { estabelecimento da interação } \\
\text { entre a escola e a comunidade do } \\
\text { interior da Bahia }\end{array}$ & $\begin{array}{c}\text { Abordagem } \\
\text { qualitativa } \\
\text { Estudo Etnográfico } \\
\text { Pesquisa-ação }\end{array}$ \\
\hline $\begin{array}{l}\text { O Projeto Institucional de Bolsas de } \\
\text { Iniciação a Docência (Pibid) com } \\
\text { Educação Ambiental no ambiente } \\
\text { escolar e na comunidade: } \\
\text { trabalhando com resíduos sólidos }\end{array}$ & 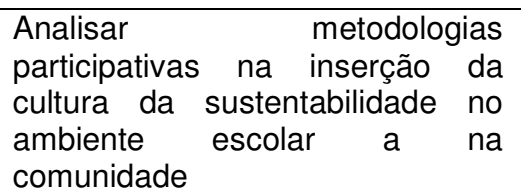 & $\begin{array}{l}\text { Abordagem } \\
\text { qualitativa } \\
\text { Estudo Etnográfico } \\
\text { Pesquisa-ação }\end{array}$ \\
\hline $\begin{array}{l}\text { Contribuições e limitações do } \\
\text { subprojeto interdisciplinar } \\
\text { educação ambiental do Programa de } \\
\text { Bolsa e Iniciação à Docência (Pibid): } \\
\text { a interação entre comu-nidade } \\
\text { escolar e comunidade local. }\end{array}$ & $\begin{array}{l}\text { Analisar as contribuições e } \\
\text { limitações do Pibid na interação } \\
\text { escola-comunidade } \\
\text { desenvolvimento de } r \text { no } \\
\text { socioambientais }\end{array}$ & $\begin{array}{c}\text { Abordagem } \\
\text { qualitativa } \\
\text { Estudo Etnográfico } \\
\text { Pesquisa-ação }\end{array}$ \\
\hline
\end{tabular}

Esse tipo de estudo é percebido como de natureza participativa, em que o pesquisador também é sujeito envolvido na pesquisa. Além de elaborar colaborativamente as ações socioambientais que serão desenvolvidas com os demais pesquisados. Conforme ilustra o depoimento do bolsista a seguir.

No viés escolar, a pesquisa-ação contribui muito para o melhoramento de minhas práticas didáticas em sala, pois permite aguçar a minha autocrítica e incitar nos alunos o seu senso crítico, em prol do bem comum. Partindo desse pressuposto, na condição de docente em formação, noto-me cada vez mais pesquisando melhorias, novidades, contribuições e adequações para o chão da escola, claro que, dentro dos meus limites e possibilidades. Acredito, ainda, que é preciso ter o aluno como o cerne de sua pesquisa-ação, ou seja, aumentar o seu leque de conhecimento com estratégias didáticas novas, com os olhos fitos não tão somente nos mais estudiosos da sala, mas principalmente nos que não se destacam nessa multidão escolar (Fernando, bolsista de Iniciação a Docência). 
A fala do bolsista acima retrata o sentido da pesquisa-ação segundo os preceitos de Tripp (2005, p. 445), que a considera como uma "estratégia para 0 desenvolvimento de professores e pesquisadores de modo que eles possam utilizar suas pesquisas para aprimorar seu ensino e, em decorrência, o aprendizado de seus alunos".

c) Encontros na escola (Figura 2): os encontros são constituídos pelas reuniões dos próprios grupos, bem como pelas ações planejadas e desenvolvidas com o objetivo de aproximar a comunidade externa da participação coletiva nos debates travados sobre as questões ambientais.

Acredito que o Pibid tem me proporcionado a aproximação com a percepção do que é uma unidade de ensino. Após iniciar minhas atividades como bolsista do Pibid me deparei com diversas dificuldades no processo de ensino-aprendizagem, e essa vivência prematura, mas orientada, auxiliará no meu processo de formação, de modo que a minha posição de docente seja a mais produtiva possível no sentido de preparar meus futuros alunos, tendo em vista as diferenças socioeconômicas e socioculturais (Igor, bolsista de Iniciação a Docência).
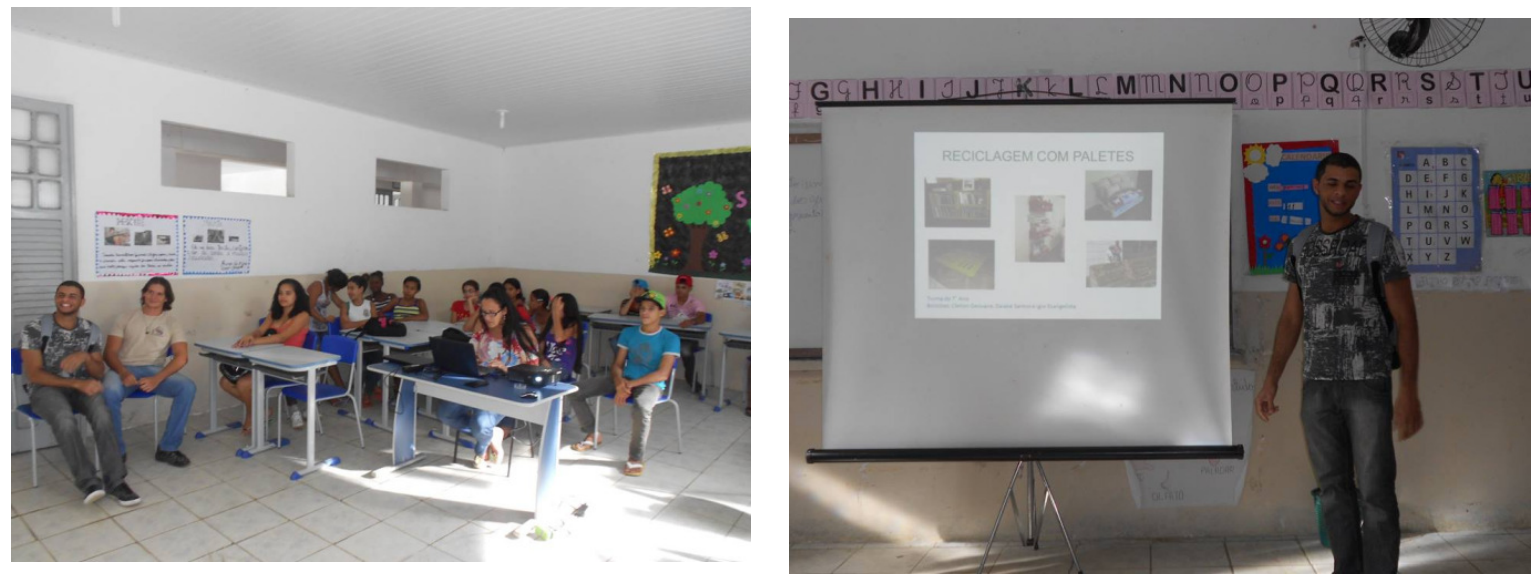

Figura 2: Bolsistas ID, professora supervisora e discentes do ensino fundamental da escola do campo em interação. Fonte: Neila Peixoto - Professora supervisora (2014)

d) Diário de bordo: é um instrumento de coleta de dados que também fornece elementos para a reflexão sobre o que está sendo observado. Com isso, os bolsistas envolvidos na linha de ação EA conseguem refletir sobre todo processo que estão analisando e de que estão participando. O diário também é socializado com os demais membros do grupo, o que torna possível um saber do desenvolvimento do outro sobre o olhar observador $e$ crítico frente aos problemas escolares e ambientais. 
O diário de bordo é um instrumento que colabora para a prática reflexiva do profissional, na medida em que promove o pensar crítico sobre o cotidiano de uma prática a partir dos processos de observação, descrição e análise do que foi vivenciado em determinado contexto (LIMA; MIOTO; DAL PRÁ, 2007). Também é considerado como um instrumento de aprendizagem e avaliação do processo educativo.

$\mathrm{Na}$ formação do professor, este instrumento potencializa as organizações de ideias e um repensar sobre o planejamento didático, mostrando a flexibilidade das ações e a possibilidade de autoavaliação da prática pedagógica.

e) Planejamento e elaboração dos materiais didáticos: de posse das análises dos estudos, são elaborados coletivamente o plano de ação que cada grupo irá desenvolver. Sempre pautados naquilo que foi constatado durante determinado período inseridos na unidade de ensino, conforme podemos observar no Quadro 2.

Quadro 2 - Parte do Planejamento dos bolsistas ID do grupo atuante na escola do campo

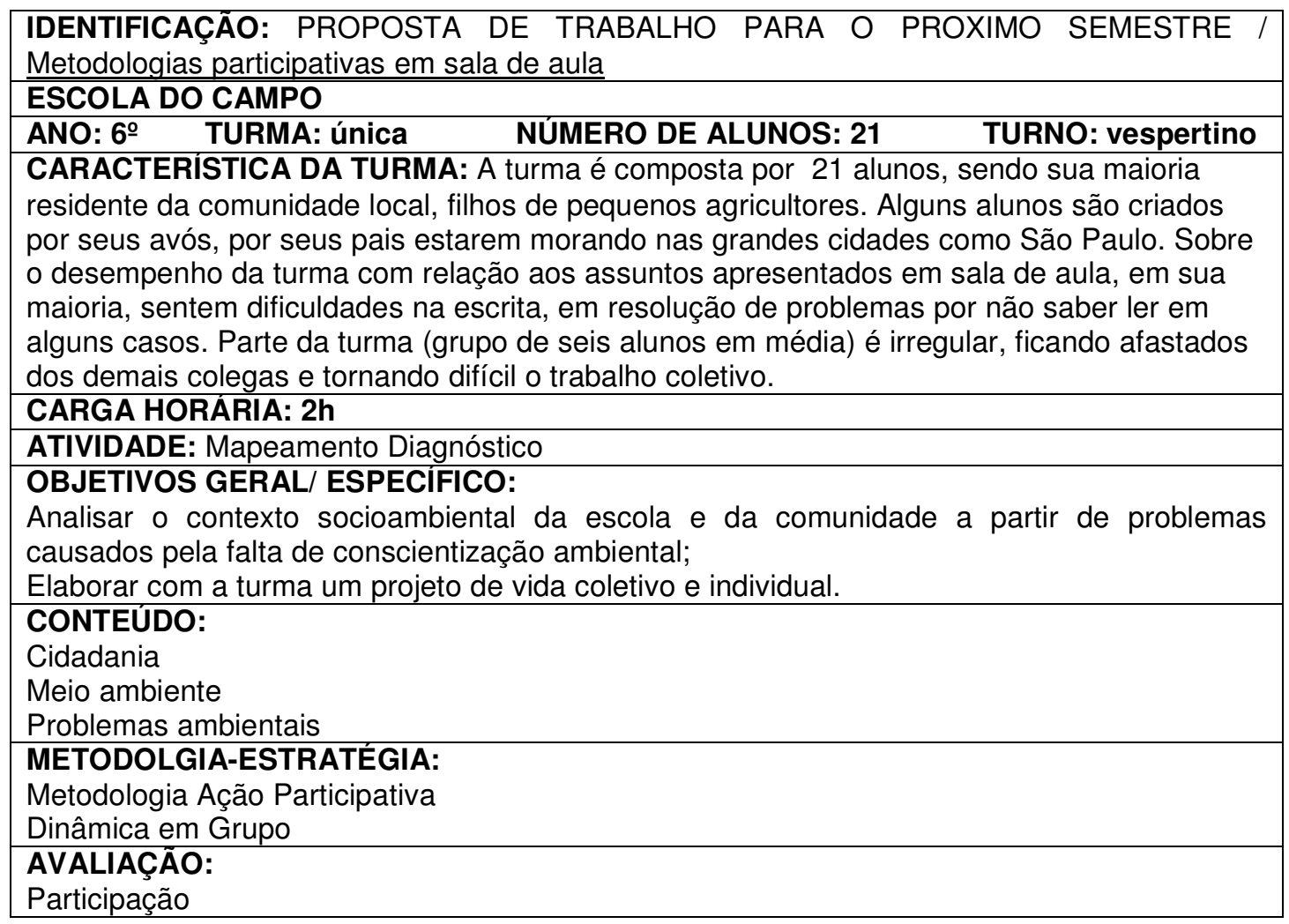

O planejamento é considerado como uma ferramenta metodológica que possibilita intervir no contexto real para transformá-lo em um contexto em que 
os atores sociais dialoguem criticamente e construam colaborativamente uma "consciência crítica a partir da reflexão sobre a prática de mudança" (SCHNEIDER, 2003, p.13), conforme está mencionado na fala da bolsista a seguir:

[...]O Pibid está sendo de suma importância, vai além da iniciação científica. A troca de informações com professores e alunos de Itaibó, a ida a campo, o popular 'mão na massa' que está fazendo toda a diferença, com informações visuais além das visualizadas nos slides das aulas teóricas, a prática da escrita que vem desde os relatos de experiência até o planejamento das aulas e a aproximação com o ato de educar (Lucivânia, bolsista de Iniciação a Docência).

f) Monitoria didática: de posse dos planejamentos, os bolsistas assumem temporariamente a sala de aula e/ou realizam oficinas didáticas (Figura 3) sob orientação das professoras supervisoras e professores colaboradores. Desta forma, eles começam a vivenciar a prática pedagógica.

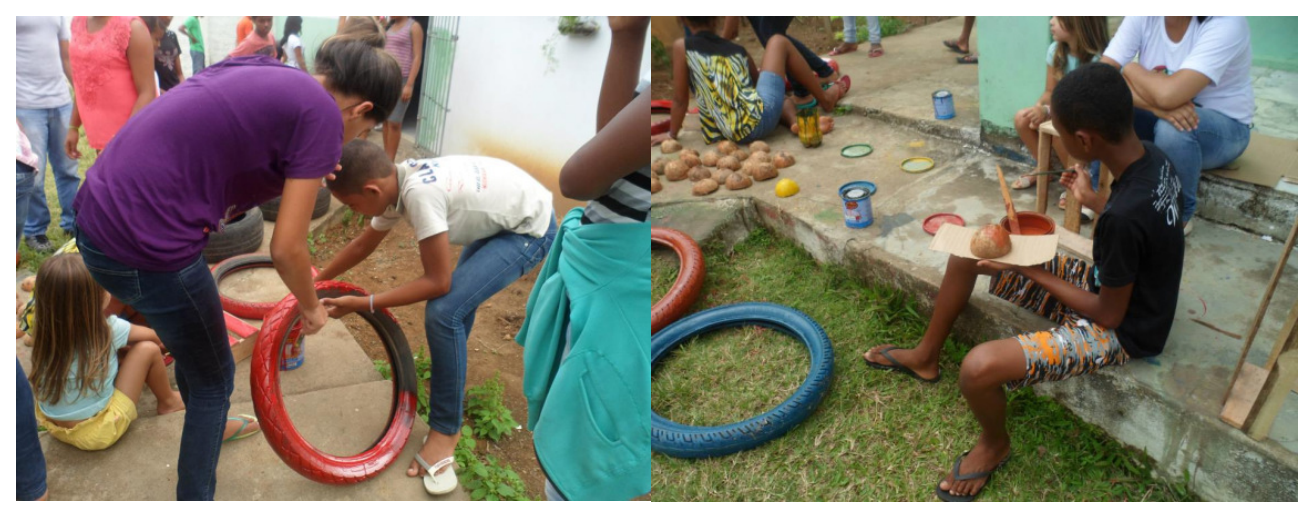

Figura 3 - Oficina de reciclagem realizada na escola do campo.

Fonte: Neila Carla Barreto Peixoto - Professora supervisora (2014)

g) Socialização dos resultados: durante todo o processo de interação, realizamos a socialização dos resultados, por meio da apresentação do estudo etnográfico, dos dados parciais da pesquisa-ação, da interação, quanto à elaboração dos planos de aula e a socialização do diário de bordo.

h) Avaliação: a avaliação formativa é processual, em que todas as ações realizadas são avaliadas pelo grupo, a partir do envolvimento, frequência, participação ativa nas reuniões, participação em eventos, produções científicas dentre outros. Nesse contexto, tentamos conduzir os atores sociais "em seu caminho na construção de conhecimentos socialmente relevantes" (LORDELO; ROSA; SANTANA, 2010, p,15). Desta forma, a avaliação se constitui como um mecanismo que orienta a prática pedagógica e fornece elementos substanciais a aprendizagem (CARNEIRO; SILVA, 2013). 


\section{Considerações finais}

O Pibid-Microrrede Ensino-Aprendizagem-Formação na perspectiva do Subprojeto Interdisciplinar: Educação ambiental, se constitui como uma rede colaborativa entre universidade-escola-comunidade. Em seus passos iniciais, tem promovido a inserção do professor em formação na trama escolar, a atualização contínua dos professores da educação básica, e possibilita ao professor universitário revisitar os seus conceitos e ações pedagógicas. Como um projeto em andamento, encontra-se em constante avaliação, a partir do ciclo contínuo: observações-elaborações de ações-desenvolvimento das ações-avaliação-observações... Primando pelas ações sustentáveis e pela capacidade de reflexão crítica da realidade socioambiental, estrutura-se nos pressupostos teóricos-metodológicos da EA voltada à formação de sujeitos socioambientalmente responsáveis.

\section{Agradecimentos:}

A Coordenação de Aperfeiçoamento de Pessoal de Nível Superior (Capes), pelas bolsas concedidas aos atores sociais do Subprojeto Interdisciplinar: Linha de Ação Educação Ambiental.

\section{Referências}

BRASIL. Ministério da Educação e Ministério do Meio Ambiente, Departamento de Educação Ambiental, Unesco. Vamos cuidar do Brasil: conceitos e práticas em educação ambiental. Brasília, 2007.

CARNEIRO, M.A.F.; SILVA, S.N. Formação inicial: a avaliação da aprendizagem no estágio supervisionado de ciências. Investigación y Experiencia Didácticas, v. especial, p. 1073-1078, 2013.

CARVALHO, I.C.M. Educação ambiental crítica: nomes e enderaçamentos da educação. In: LAYRARGUES, P.P. (Org.). Identidades da educação ambiental brasileira. Brasília: Ed. do Ministério do Meio Ambiente, 2008. p. 13-24.

GERHARDT, C.H.; ALMEIDA, J. A dialética dos campos sociais na interpretação da problemática ambiental: uma análise crítica a partir de diferentes leituras sobre problemas ambientais. Ambiente \& Sociedade, Campinas, v. 3, n. 2, p. 1-34, 2005.

LLARENA, M.A.A. O estudo do meio uma alternativa metodológica para abordagem de problemas ambientais urbanos na escola básica. Dissertação de Mestrado. Programa de Pós-Graduação em Geografia. Universidade Federal da Paraíba, João Pessoa-PB, 2009. 164p.

LEFF, E. Ecología y capital: racionalidad ambiental, democracia participativa y desarrollo sustentable. México: Siglo XXI, 2005. 
LIMA, T.C.S.; MIOTO, R.C.T.; DAL PRÁ, K.R. A documentação no cotidiano da intervenção dos assistentes sociais: algumas considerações acerca do diário de campo. Textos \& Contextos Porto Alegre, v. 6, n. 1, p. 93-104, 2007.

LORDÊLO, J.A.C.; ROSA, D.L. SANTANA, L.A. Avaliação processual da aprendizagem e regulação pedagógica no Brasil: implicações no cotidiano docente. R. Faced, Salvador, n.17, p.13-33, jan. /jun. 2010.

LOUREIRO, C.F.B. Teoria social e questão ambiental: pressupostos para uma práxis crítica em educação ambiental. In: LOUREIRO, C.F.B.; LAYRARGUES, P.P.; CASTRO, R.S. (Org.). Sociedade e meio ambiente: a educação ambiental em debate. São Paulo: Cortez, 2002. p. 13-52.

LOUREIRO, C.F.B. et al. Problematizando conceitos: contribuição à práxis em educação ambiental. In: LOUREIRO, C.F. et al. (Org.). Pensamento complexo: dialética e educação ambiental. São Paulo: Cortez, 2006. p.104161.

LOUREIRO, C.F.B.; CASSIO, M.B. Educação ambiental crítica: contribuições e desafios. In: BRASIL, Ministério da Educação e Ministério do Meio Ambiente, Departamento de Educação Ambiental, UNESCO. Vamos cuidar do Brasil: conceitos e práticas em educação ambiental. Brasília, 2007. p. 57-64.

MELO; M.C.H.; CRUZ; G.C. Roda de conversa: uma proposta metodológica para a construção de um espaço de diálogo no ensino médio. Imagens da Educação, Maringá/PR, v. 4, n. 2, p. 31-39, 2014.

MIRANDA, M.I. Pesquisa-ação escolar: uma alternativa de enfrentamento aos desafios educacionais. In: SILVA, L.C.; MIRANDA, M.I. (Org.). Pesquisa-ação: uma alternativa à práxis educacional. Uberlândia/MG: Edufu, 2012. p. 13-28.

PIBID-UESB. Projeto Institucional 2014. Programa Institucional de Bolsas de Iniciação a Docência da Universidade Estadual do Sudoeste da Bahia: Microrrede Ensino - Aprendizagem- Formação. Disponível em $<$ http://pibid.uesb.br/ava/mod/ resource/view.php?id=5254>. Acesso em: 14 ago. 2014.

SCHNEIDER, M.S.P.S. O planejamento de aula em dois contextos: do institucional ao colaborativo. Dissertação de Mestrado. Pontifícia Universidade Católica de São Paulo. São Paulo-SP, 2003, 133p.

TRIPP, D. Pesquisa-ação: uma introdução metodológica. Educação e Pesquisa, São Paulo, v. 31, n. 3, p. 443-466, 2005.

VELOSO, N. Entre camelos e galinhas, uma discussão acerca da vida na escola. In: BRASIL, Ministério da Educação e Ministério do Meio Ambiente, Departamento de Educação Ambiental, UNESCO. Vamos cuidar do Brasil: conceitos e práticas em educação ambiental. Brasília, 2007, p. 73-84.

WIELEWICKI, V.H. A pesquisa etnográfica como construção discursiva. Acta Scientiarum, Maringá, v. 23, n.1, p. 27-32, 2001. 